\title{
A New Year
}

\section{COLLEGE \\ G RESEARCH \\ LIBRARIES}

We greet 1975 with a new design for College $b$ Research Libraries and trust our readers will welcome with pleasure its changed appearance. We also begin this year with a new editorial staff for the journal. Elaine Downing, State University College, Oneonta, New York, serves as Assistant Editor; and Mary Frances Collins, State University of New York at Albany, begins editorship of College \& Research Libraries News. Anne Dowling, also at the State University of New York at Albany, serves as Associate News Editor.

College \& Research Libraries in its two formats-a bimonthly technical journal with eleven monthly News issues-is the basic medium for professional communication among librarians in our colleges, universities, and research institutions.

In its role as the official journal of the Association of College and Research Libraries, the periodical also has a special mission in sharing with academic and research librarians reports on the ongoing work of ACRL. Recent issues of the News with statements on standards for college libraries and guidelines for branch libraries bear testimony to the importance of ACRL in the maintenance and improvement of library service.

This new year also brings a changed dues schedule for the American Library Association. Under this schedule, voted by the membership last year, members through annual dues of thirty-five dollars will have a basic membership in ALA. No longer do we check off our "two divisions"; instead, we are obliged to make specific choices of the divisions we join and then support those choices with additional dues.

A recent sample survey of ALA members has indicated that each division will probably lose a substantial number of its members because of the changed dues structure. Already it appears some planning is underway on how to curtail division programs because of lessened financial support.

We have the opportunity in ACRL to prove the error of this survey and to indicate through our membership that ACRL will flourish.

As the pages of College \& Research Libraries show, the programs of ACRL are many and worthwhile; ACRL deserves our support so that it may remain the national spokesman for college, university, and research librarians. A major program of ACRL is publication, and this journal is the principal example of that program. It is a tangible benefit of membership, and the present editorial staff is devoted to its continued improvement. We begin 1975 with optimism and commitment to ACRL and ALA.

R.D.J. 


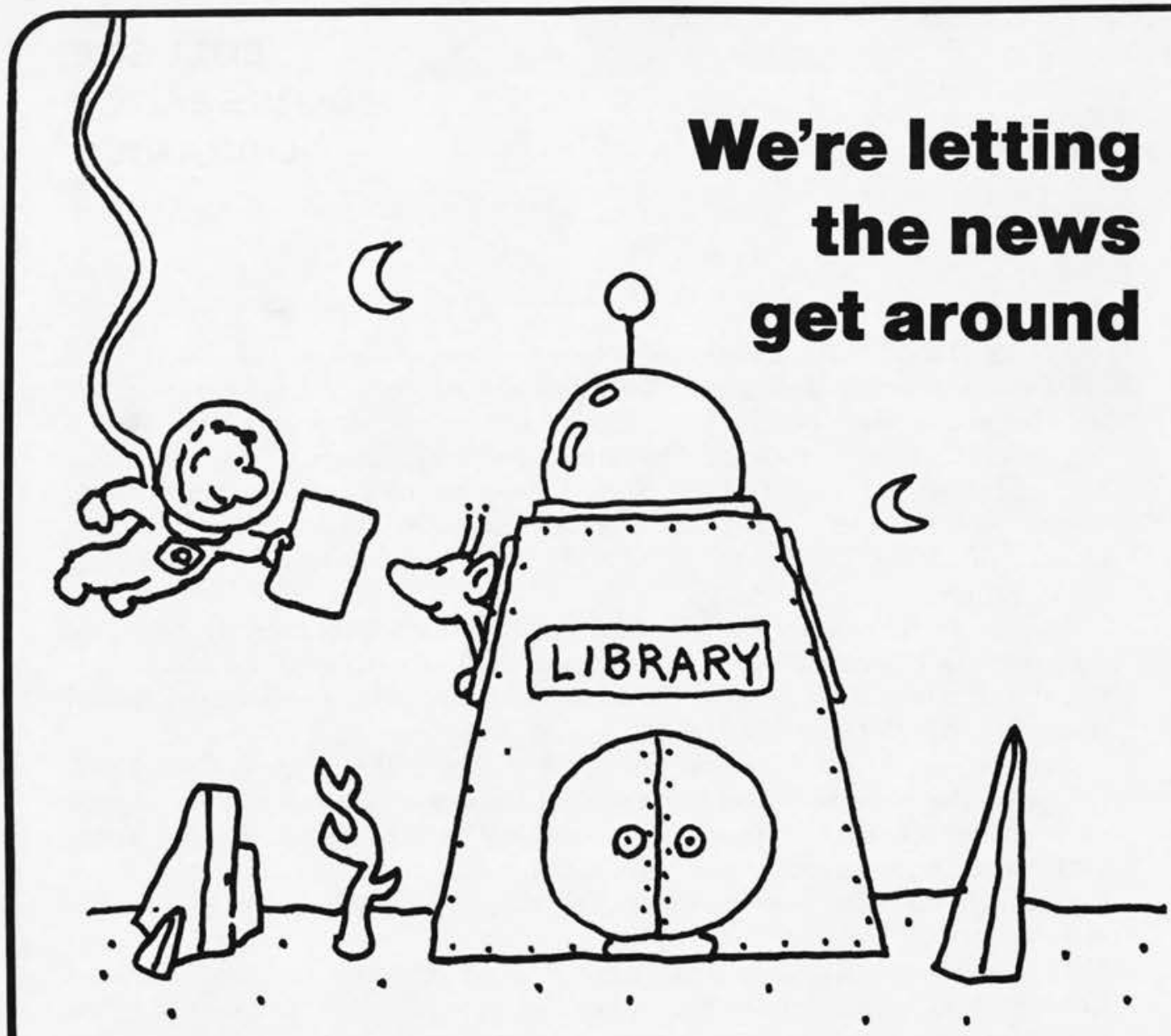

For the first time, american libraries is available to all libraries-on subscription. (And, of course, anyone can have it as part of ALA membership, now available at a new low cost for individuals.)

What's more, american libraries is launching out in a bold new direction never fully achieved in the library press: Association, professional, national and local news without tears. Who says an official journal has to be dull? Not the new AL editor, who brings two Educational Press Association Awards of his own to add to the six that AL won in 1973.

There'll be plenty of hard news in AL these hard times. Isn't it good news that you can subscribe for your library by just checking the form below?

\section{american Iibraries}

Subscriptions Dept., 50 East Huron St., Chicago 60611

Please send subscription(s) for year(s) (11 issues per year, $\$ 20.00$ )

Send to:

\begin{tabular}{lll}
\hline Institution & & \\
\hline & & \\
\hline Address & & \\
\hline City & State & Zip
\end{tabular}

Bill to:

\begin{tabular}{lll}
\hline Institution & & \\
\hline & & \\
\hline Address & & \\
\hline City & State & Zip
\end{tabular}

